\title{
INTERNACIONALIZAÇÃO DE EMPRESAS E GOVERNANÇA CORPORATIVA: UMA ANÁLISE DAS MAIORES COMPANHIAS ABERTAS DO BRASIL
}

\author{
José Glauber Cavalcante dos Santos ${ }^{1}$ \\ Alessandra Carvalho de Vasconcelos ${ }^{2}$ \\ Márcia Martins Mendes De Luca ${ }^{3}$
}

Resumo: Respaldada pela ótica da Economia dos Custos de Transação, neste trabalho verifica-se a relação entre a internacionalização, na perspectiva de uma orientação estratégica multidimensional, e a governança corporativa das maiores companhias abertas do Brasil, em 31/12/2012. De natureza quantitativa, o estudo utiliza o teste de Mann-Whitney e a Regressão Linear Múltipla. Foram consideradas quatro dimensões da internacionalização, a saber: capital social, receitas, mercados e emissão de American Depositary Receipt (ADR). À governança corporativa, adaptou-se o índice de Lameira e Ness (2011), contemplando as dimensões: estrutura de propriedade, adequação ao ambiente institucional, auditoria e conselho fiscal, conselho de administração e outros, e relacionamento com investidores. Os resultados apontaram distintos graus de inserção internacional das empresas e níveis médios de governança corporativa. Verificou-se que as empresas utilizam como estratégia para a internacionalização o capital social, a emissão de ADRs, as exportações e a instalação em outros países, nessa ordem de importância. Foram observados níveis distintos de governança, confrontando-se empresas internacionalizadas com as empresas não internacionalizadas. Identificou-se influência positiva e significativa da estratégia de internacionalização na governança corporativa, revelando-se esta uma provável redutora dos custos de transação no mercado externo.

Palavras-chave: Internacionalização. Governança corporativa. Economia dos custos de transação.

\footnotetext{
E-mail: jglauber_cont@hotmail.com - Universidade Federal do Ceará

E-mail: alevasconcelos.ufc@gmail.com - Universidade Federal do Ceará

${ }^{3}$ E-mail: marciadeluca@ufc.br - Universidade Federal do Ceará

- DOI: http://dx.doi.org/10.14392/asaa.2015080302

- Artigo recebido em 27/11/2014. Revisōes requeridas em: 24/07/2015. Comunicação entre editor/autor: 15/08/2015 e aprovado em 15/08/2015.
} 


\title{
INTERNATIONALIZATION OF COMPANIES AND CORPORATE GOVERNANCE: AN ANALYSIS OF LARGERPUBLIC COMPANIES IN
}

\begin{abstract}
Based on the perspective of Transaction Cost Economics, in this paper, a relation between internationalization, from the perspective of a multidimensional strategy orientation, and corporate governance has been verified in larger public companies in Brazil on 31/12/2012. This quantitative study employs Mann-Whitney's Test and Multiple Linear Regression. Four dimensions of internationalization have been considered: capital, revenues, markets and issue of American Depositary Receipt (ADR). Lameira and Ness's Index (2011) was adapted for corporate governance, while contemplating the following dimensions: ownership structure, adequacy to institutional environment, fiscal council and auditing, board and others, and investors relation. It has been verified that companies use the ownership structure, the issue of ADRs, the export revenue and installation in other countries, in this order of importance, as internationalization strategies. Distinct levels of governance have been observed by comparing internationalized companies with non-internationalized companies. A positive and significant influence by internationalization strategies was identified in corporate governance, which reveals that it is likely a reducing factor of transaction costs in foreign markets.
\end{abstract}

Keywords: Internationalization. Corporate governance. Transaction cost economics. 


\section{INTRODUÇÃO}

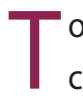
omada como uma orientação estratégica organizacional, a internacionalização pode internacionalização pode impactar significativamente as estruturas das empresas, devido às exigências competitivas do mercado internacional, para além daquelas cumpridas apenas no país de origem. Uma dessas estruturas afetadas pela internacionalização é a governança corporativa.

Silveira (2008, p. 34) destaca como motivadora da internacionalização"a sinalização aos investidores de que a empresa possui acesso a mercados onde as práticas de governança e as exigências de disclosure são mais restritivas que em seus mercados de origem". Ratifica-se o exposto, quando Domeneghetti e Meir (2009) referem que as empresas com níveis elevados de governança corporativa atraem mais investidores, reduzem seu custo de capital e valorizam suas ações. Portanto, depreende-se que a governança pode ser tomada como um mecanismo que contribui para atrair investimentos estrangeiros e facilitar a inserção da empresa nesse tipo de ambiente.

Maia, Vasconcelos e De Luca (2013) reforçam essa construção teórica ao ressaltar que as empresas que adotam boas práticas de governança sofrem pressões para disponibilizar informações qualificadas. Ao atender a essas pressões, elas promovem a redução das incertezas dos investidores. Na compreensão de Duarte, Cardozo e Vicente (2012, p. 116), “a possibilidade de captação de recursos financeiros estrangeiros traz a necessidade de adaptação e adoção de padrões de governança corporativa". No Brasil, essa postura se evidencia ainda mais relevante, já que, nas economias emergentes, o aprimoramento das estruturas de governança é anterior ao desenvolvimento do mercado de capitais (Duarte, Cardozo \& Vicente, 2012).

Assim, seguindo-se as evidências teóricas apresentadas, advoga-se que a internacionalização atua como imperativo da adoção de boas práticas de governança, devido à necessidade de captação de investimentos provenientes do exterior e de redução dos custos de transação. Emerge, então, a seguinte questão-problema: Qual a relação entre a internacionalização e a governança corporativa nas maiores companhias de capital aberto do Brasil? Destarte, constitui objetivo deste estudo verificara relação entre a internacionalização e a governança corporativa, especificamente no contexto brasileiro. Levanta-se como hipótese geral que a orientação estratégica da empresa com foco no mercado externo influencia estatística e significativamente a governança corporativa.

A sinergia entre os dois constructos - internacionalização e governança corporativa -, evidenciada em pesquisas nacionais (Silveira \& Barros, 2008; Procianoy \& Verdi, 2009; Souza, Murcia \& Marcon, 2011; Santos, Almeida \& Bezerra, 2013) e estrangeiras (Sherman, Kashlak \& Joshi, 1998; Wang, Hsu \& Fang, 2008; Singh \& Gaur, 2013; Xiao et al, 2013), tem demonstrado a relevância desse debate. Apesar disso, é oportuno destacar que o estudo simultâneo das temáticas não se mostra exaustivo.

Acerca da estratégia internacionalização, nos estudos nacionais, verifica-se a emissão de American Depositary Receipt (ADR) como medida predominante desse constructo, quando relacionada à governança corporativa. Por seu turno, nos estudos estrangeiros, nota-se que há maior diversidade de métricas (receitas, investimentos e ativos externos, por exemplo), prevalecendo, porém, a perspectiva unidimensional (apenas uma variável) da internacionalização. 
Assim, é possível considerar que essa seja uma limitação da literatura, ao posicionar-se, esta pesquisa, em favor da argumentação de Floriani e Fleury (2012), destacando que a internacionalização carece de exame multidimensional, já que engloba, além do envolvimento internacional, a adaptação estratégica de recursos e da estrutura, evidenciando-se essa visão como a mais apropriada à análise da internacionalização das empresas. Do exposto, este estudo contribui para a ampliação do escopo de avaliação do constructo internacionalização, tomado aqui por quatro perspectivas distintas (capital social, receitas, dispersão operacional e emissão de ADRs) junto à governança corporativa, suportada essa análise pela Economia dos Custos de Transação (ECT), contribuindo, assim, para o avanço de ambas as temáticas no campo teórico.

\section{INTERNACIONALIZAÇÃO DE EMPRESAS, GOVERNANÇA E A ECT}

O panorama econômico mundial revela que nas empresas brasileiras em busca de elevados padrões de competitividade, a estratégia de internacionalização pode mostrar-se imprescindível (Arantes, Mottin \& Gomes, 2010). Assim, segundo Milan et al (2013), as motivações pela internacionalização podem derivar de objetivos diversos, destacando-se a atuação em outros mercados, o combate à concorrência e a redução de custos.

A propósito, Muller (2008) esclarece que, apesar de muitos estudos enfatizarem a redução do risco como principal benefício da internacionalização, devido à pluralização do escopo geográfico de atuação, há diversos outros riscos difíceis de serem minimizados, pois não sofrem o efeito (positivo) da diversificação. Talvez por essa razão, Burgman (1996) afirmou que a diversificação internacional não reduz a volatilidade dos lucros das empresas; e Reeb, Kwok e Baek (1998) encontraram relação positiva entre o grau de internacionalização e o risco sistemático das empresas.

Nesta pesquisa, devido a seu foco, dá-se atenção a dois dos principais tipos de risco - não diversificáveis - decorrentes da internacionalização: (i) o risco associado ao conflito de interesses e (ii) o risco da assimetria informacional (Muller, 2008), que tendem a elevar os custos de transação das empresas.

Nas empresas internacionalizadas, os custos de transação decorrentes do conflito de interesses são maiores que aqueles observados em empresas que atuam somente no mercado interno (Burgman, 1996). O conflito de interesses torna-se importante componente do risco da atuação da empresa no mercado externo, porque tende ao crescimento à medida que se eleva a expansão internacional. $\mathrm{O}$ monitoramento do agente, nesse sentido, é mais dispendioso para a empresa em função de fatores como as limitações geográficas, distinções de caráter cultural e diferenças entre os sistemas contábil e legal de cada país (Muller, 2008).

Por sua vez, seguindo essa mesma lógica, o risco relacionado à assimetria informacional também é crítico, porque, como o monitoramento e o controle tendem a se tornar cada dia mais complexos e menos eficientes na internacionalização das empresas (Gomes \& Martinewski, 2001), também existirá assimetria informacional envolvendo matriz e subsidiárias, o que também faz elevar os custos de transação.

Portanto, a partir desta breve discussão, pode-se considerar a potencial contribuição que a governança corporativa teria quando aplicada como instrumento na mitigação dos tipos de risco supracitados. Demonstra-se o quão pertinente é a adoção de boas práticas de governança corporativa pelas empresas, em especial no ambiente internacional. Como se vê em Maia, Vasconcelos e De Luca (2013, p. 45), "a governança corporativa possui alguns instrumentos que permitem mitigar a assimetria informacional e o oportunismo dos agentes, e estimular a internacionalização". As autoras concluíram que 
a internacionalização do capital social é sinalizada pela governança corporativa, em empresas do setor de construção e transportes listadas na BM\&F Bovespa.

Na presente pesquisa, a definição de governança corporativa compreende um arcabouço de princípios e práticas que procuram minimizar conflitos de interesse entre stakeholders, maximizar o valor da empresa e aumentar o retorno dos acionistas (ANDRADE, 2008). O objetivo da governança corporativa, portanto, abarca a diminuição dos custos e os riscos relativos ao conflito de interesses, à assimetria informacional e à percepção de incerteza do investidor acerca do ambiente internacional. Neste instante, cabem as considerações de Nickels e Wood (1999), por exporem que, à medida que aumenta o nível de internacionalização da empresa, cresce também a demanda por mecanismos de controle. Desse modo, sendo a exportação o meio mais frequente de internacionalização, segundo Floriani e Fleury (2012), envolve menos risco, comprometimento e controle que uma joint venture e que o investimento direto.

Pelo fato de o contexto social internacionalizado ser aberto e dinâmico, gerando dificuldades na previsão de mudanças e na identificação de impactos, torna-se importante a adaptação estratégica e estrutural da empresa em função das demandas do mercado, através de mecanismos de controle formais e informais (Lopes \& Gomes, 2013). Como a demanda por informações relevantes das empresas, pelas partes interessadas (stakeholders), é determinada pelo modelo de governança corporativa dominante no país (Ojah \& Mokoaleli-Mokoteli, 2012), é possível deduzir que as estruturas de governança adotadas pelas firmas estão relacionadas com a sua estratégia internacional (Lin, 2012).

Conforme demonstram Oesterle, Richta e Fish (2013), os gestores de diversificação internacional possuem incentivos para reduzir o valor da empresa; logo, também existe incentivo para instalação de mecanismos de governança que evitem o comportamento gerencial oportunista e se reduzam os custos de transação. Além disso, "a disponibilidade de informações com qualidade prestadas ao mercado faz a diferença entre uma decisão de investimento (estrangeiro) ser boa ou não" (Andrade, 2008, p. 41).

Pela ótica da ECT, Coase (1937) e Okimura (2003) definem empresa como uma estrutura de governança, capaz de minimizar os custos de transação (custos dos contratos) derivados das ações oportunistas dos agentes. Para Williamson (1996), se não fossem a racionalidade limitada e o oportunismo, findariam todos os problemas da organização econômica complexa. Ainda, de acordo com Williamson (1996), o direito contratual desempenha papel ativo nessa teoria, que, segundo Hoque (2010), vê na transação a mínima célula de análise. Segundo a ECT, "um sistema eficiente de governança deverá elaborar mecanismos de incentivos, contingências para a resolução de conflitos de forma a promover a continuidade das transações e que sejam eficientes na ausência de oportunismos" (Okimura, 2003, p. 14).

Portanto, tomando-se por base todas essas considerações, a governança corporativa afigura-se necessária ao processo de internacionalização das empresas, pois corrobora a mitigação dos conflitos de interesse e da assimetria informacional, riscos provenientes da diversificação internacional das atividades da empresa. Assegura-se que a redução de tais riscos tem impacto positivo nos custos de transação da firma, sendo a governança corporativa o mecanismo de controle e monitoramento de ações oportunistas da gestão, benéfica à internacionalização. É sob essa argumentação que a presente pesquisa encontra justificativa.

Deve-se ressaltar que, à semelhança da proposta objeto deste estudo, algumas pesquisas nacionais evidenciam a relação entre a internacionalização e a governança corporativa (Silveira \& Barros, 2008; Procianoy \& Verdi, 2009; Souza, Murcia \& Marcon, 2011; Cunha, 2012; Mapurunga, Ponte \& Oliveira, 
2013; Santos, Almeida \& Bezerra, 2013), além de estudos estrangeiros (Sherman, Kashlak \& Joshi, 1998; Hassel et al, 2003; Wang, Hsu \& Fang, 2008; Kontinen \& Ojala, 2010; Singh \& Gaur, 2013; Xiao et al, 2013).

Todavia, apesar dos múltiplos direcionamentos dados às investigações pesquisadas, não se observou nenhuma análise adotando como base teórica a ECT, como se propõe nesta pesquisa, conjunta à perspectiva multidimensional da internacionalização. Ou seja, a estratégia de internacionalização, em suas diversas óticas de análise, impactando as práticas de governança corporativa adotadas pelas empresas, apresenta-se como análise diferenciada.

Destarte, à luz da articulação teórica até aqui delineada, elaborou-se a proposta de modelo teórico de análise deste estudo (Figura 1), em que se defende a ocorrência de interação da internacionalização com a governança corporativa pela ótica da ECT.

Figura 1: Proposta do modelo teórico de análise da pesquisa Mercado Externo

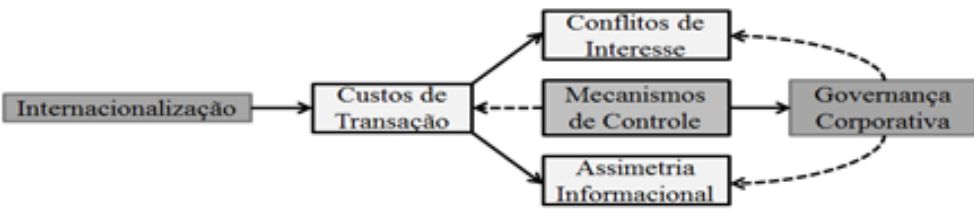

Economia dos Custos de Transação

Fonte: elaboração própria

Da Figura 1, pressupõe-se que, ao participar efetivamente do mercado internacional, conforme definido na sua orientação estratégica, a empresa eleva seus níveis de governança corporativa, através de mecanismos de controle, com vistas à redução dos custos de transação (trade-off). Em decorrência disso, atrai o investimento externo mais facilmente, porque se reduzem o conflito de interesses e a assimetria informacional, riscos inerentes à internacionalização. Por esse motivo, acredita-se que a governança corporativa se torna um requisito do processo de internacionalização da empresa. Para Smaniotto, Paiva e Vieira (2012), sempre que a empresa atua em nível global, é imprescindível delinear a sua estrutura para a maximização da competitividade. Nesta pesquisa, a estrutura de governança é um recurso que torna a empresa mais competitiva.

Diante do exposto, supõe-se que a internacionalização poderá influenciar as práticas de governança corporativa adotadas pelas empresas (hipótese geral do estudo). Antes de apresentar os procedimentos metodológicos deste estudo, cabe esclarecer o posicionamento que justifica a adoção da perspectiva multidimensional de análise da internacionalização.

Floriani e Fleury (2012) expõem a ótica de estudo da internacionalização considerando aspectos como as variações de dotação de recursos, de oportunidades de mercado e capacidades gerenciais, dentro da firma. Em outras palavras, leva-se em conta a mensuração da internacionalização baseada em múltiplos indicadores. Essa abordagem, mais preocupada com aspectos econômicos, direciona a realização deste estudo, pois se considera a internacionalização um constructo multidimensional, assim como nas pesquisas de Sullivan (1994), Hassel et al (2003) e Ruigrok e Wagner (2003). Por essa mesma ótica, Carneiro e Dib (2007) entendem que a internacionalização é um processo dotado de complexidade e variabilidade.

Além dessas considerações, reforça-se a opção pela perspectiva econômica por meio do emprego da ECT, uma das teorias econômicas que explicam a internacionalização (Export Manager, 2008; Santos, 2009).

As métricas utilizadas para mensurar a internacionalização das empresas são diversas, porém não se percebe uma convergência na aplicação de métodos e procedimentos necessários ao alcance desse 
objetivo (Sullivan, 1994). Apesar disso, algumas métricas são preponderantes, sendo frequentemente utilizadas em pesquisas que tenham como foco a internacionalização e, com menor frequência, a governança corporativa conjuntamente. Destacam-se as seguintes medidas aplicadas em alguns estudos: (i) internacionalização do capital social da empresa - parcela de estrangeiros acionistas (Maia, Vasconcelos \& De Luca, 2013; Santos, Vasconcelos \& De Luca, 2013), (ii) internacionalização das receitas - receitas estrangeiras (Sullivan, 1994; Floriani \& Fleury, 2012), (iii) internacionalização dos mercados - número de países onde atua a empresa (Platchek, Floriani \& Borini, 2012; Mitter et al, 2012, Duller et al, 2012) e (iv) internacionalização por meio de ADRs -emissão de ADRs (Souza, Murcia \& Marcon, 2011; Santos, Almeida \& Bezerra, 2013; Mapurunga, Ponte \& Oliveira, 2013).

Dessa forma, para atender ao objetivo da pesquisa, diante do enfoque multidimensional dado pela presente investigação e em razão das recomendações apresentadas na literatura, bem como das diversas métricas de internacionalização, elenca-se, mais especificamente, a hipótese a ser testada: a internacionalização, medida através de quatro perspectivas distintas - capital social, receitas derivadas do exterior, dispersão geográfica e emissão de American Depositary Receipt (ADR) -, influencia as práticas de governança corporativa das empresas brasileiras.

Reitera-se que, para se tornar competitiva e atrair o stakeholder estrangeiro, as empresas, de maneira uniforme, adotam a internacionalização como conduta (Faro \& Faro, 2010; Heijltjes, Olie \& Glunk, 2003) e seguem padrões globalizados de governança alinhados com a sua estratégia internacional (Lin, 2012). Assim sendo, para investidores estrangeiros, a governança é fator relevante no processo decisório.

\section{MÉTODO DE PESQUISA}

\subsection{AMOSTRA, COLETA E TRATAMENTO DOS DADOS}

A população da pesquisa reúne as 100 maiores empresas de capital aberto do Brasil, de acordo com a Revista Exame Melhores e Maiores (edição 2013). A amostra exclui apenas a empresa Amil, que no período de coleta dos dados não se encontrava listada na BM\&F Bovespa.

Foram utilizados dados secundários oriundos das Demonstrações Financeiras Padronizadas (DFP) e demais relatórios alusivos às empresas da amostra (Formulário Referência e Formulário Cadastral), disponíveis no portal eletrônico da BM\&F Bovespa. O período de análise é o exercício social de 2012. Além desses documentos, foi utilizado o banco de dados do JP Morgan's ADR (https://www.adr.com/ DRSearch/CustomDRSearch\#). A coleta de dados foi realizada em setembro e outubro de 2013.

Especificamente na etapa de coleta dos dados, inicialmente recorreu-se à análise de conteúdo, aplicada aos documentos das empresas, em especial ao Formulário de Referência, de onde se extraiu a maior parte dos dados de internacionalização e governança corporativa demandados nesta análise. Com a análise de conteúdo, informações suplementares são fornecidas ao pesquisador, que percorre as fases de pré-análise (seleção do material), exploração do material (documentos), tratamento dos resultados, inferência e interpretação (Bardin, 1977).

Concluída essa etapa, e de posse dos dados relativos aos dois constructos teóricos confrontados neste estudo, em seguida desenvolveu-se o tratamento quantitativo dos dados, utilizando-se o teste de diferenças entre médias e a regressão linear múltipla, com a finalidade de verificação da hipótese de pesquisa. 


\subsection{DEFINIÇÃO DAS VARIÁVEIS}

No Quadro 1 são evidenciadas as variáveis independentes, bem como suas métricas, fonte de coleta dos dados e a base teórica que suporta a utilização da medida como representativa do constructo internacionalização. Cabe ressaltar que no presente estudo todas essas variáveis são consideradas influentes na governança corporativa das empresas.

Quadro 1: Variáveis independentes do constructo internacionalização

\begin{tabular}{|c|c|c|c|c|}
\hline Variável & Métrica utilizada & \multicolumn{2}{|c|}{ Fonte de coleta } & Aporte teórico \\
\hline $\begin{array}{l}\text { Internacionalização do capital } \\
\text { social }\end{array}$ & $\begin{array}{l}\text { Participação de acionistas } \\
\text { estrangeiros no capital social }\end{array}$ & \multirow{3}{*}{$\begin{array}{l}\text { Formulário de } \\
\text { Referência }\end{array}$} & $\begin{array}{l}\text { Item } 15.1 / 2 \\
\text { - Posição } \\
\text { acionária }\end{array}$ & $\begin{array}{l}\text { Masullo e Lemme (2009); } \\
\text { Maia, Vasconcelos e De Luca (2013); } \\
\text { Santos, Vasconcelos e De Luca (2013) }\end{array}$ \\
\hline Internacionalização das receitas & $\begin{array}{c}\text { Proporção de receitas derivadas do } \\
\text { exterior }\end{array}$ & & $\begin{array}{l}\text { Item } 7.7 \\
\text { - Receitas } \\
\text { relevantes no } \\
\text { exterior }\end{array}$ & $\begin{array}{c}\text { Sullivan (1994); Ruigrok e Wagner } \\
\text { (2003); Hassel et al (2003); Platchek, } \\
\text { Floriani e Borini (2012); Mitteret al. } \\
\text { (2012) }\end{array}$ \\
\hline Internacionalização dos mercados & $\begin{array}{l}\text { Quantidade de países onde a } \\
\text { empresa tem instalações }\end{array}$ & & $\begin{array}{c}\text { Item } 7.1 \\
\text { - Descrição- } \\
\text { atividades do } \\
\text { emissor/ } \\
\text { controladas }\end{array}$ & $\begin{array}{l}\text { Machado-da-Silva e Fernandes } \\
\text { (1999); Ruigrok e Wagner (2003); } \\
\text { Floriani e Fleury (2012) }\end{array}$ \\
\hline $\begin{array}{c}\text { Internacionalização por meio } \\
\text { de ADRs }\end{array}$ & Emissão de ADRs & \multicolumn{2}{|c|}{ JP Morgan's ADR } & $\begin{array}{c}\text { Procianoy e Verdi (2009); Souza, } \\
\text { Murcia e Marcon (2011); Santos, } \\
\text { Almeida e Bezerra (2013); } \\
\text { Mapurunga, Ponte e Oliveira (2013). }\end{array}$ \\
\hline
\end{tabular}

Fonte: Elaborado pelos autores, com base na revisão da literatura.

Como demanda para atender ao objetivo geral da pesquisa, fez-se necessária, também, a construção de uma medida de governança corporativa das empresas da amostra. Para esse fim, foi elaborado um checklist que contribuiu para a obtenção de um índice de governança, como mostra o Quadro 2.

Quadro 2: Checklist para construção da variável do constructo governança corporativa

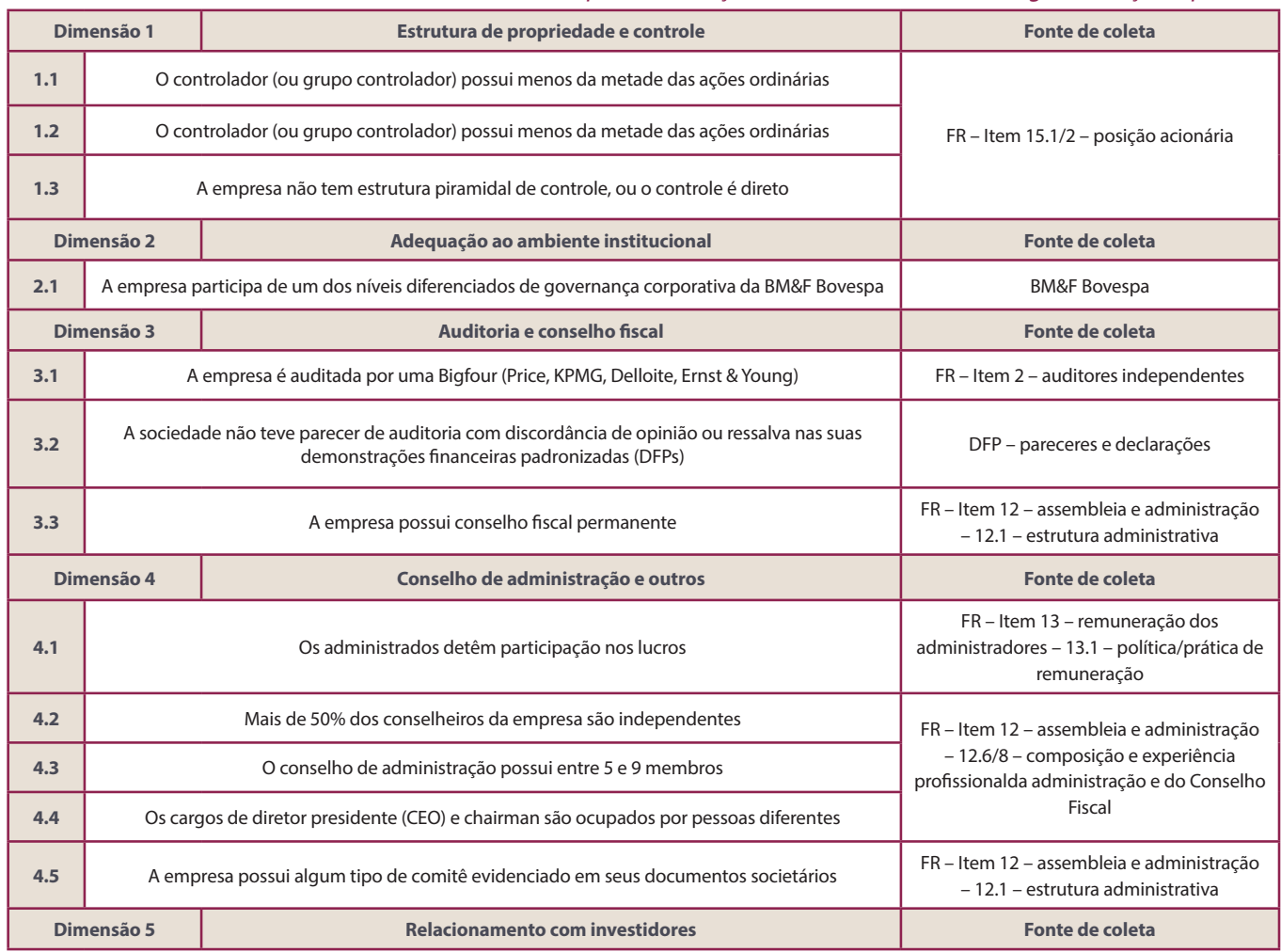




\begin{tabular}{|c|c|c|}
\hline $\mathbf{5 . 1}$ & Há na empresa investidor institucional com participação superior a 5\% do capital social & FR - Item 15.1/2 - posição acionária \\
\hline $\mathbf{5 . 2}$ & A empresa não precisou reapresentar suas demonstraçães contábeis no período investigado & DFP - motivos da reapresentação \\
\hline $\mathbf{5 . 3}$ & A empresa possui em seu portal eletrônico área dedicada à governança corporativa & Website institucional das empresas \\
\hline
\end{tabular}

O referido índice tem como base constituinte o estudo de Lameira e Ness (2011), que se propôs a examinar os determinantes das práticas de governança corporativa, também em empresas de capital aberto no contexto brasileiro, semelhantemente a esta investigação. Foram utilizados 15 itens, distribuídos em cinco diferentes dimensões (Quadro 2). Quando da verificação do item nas fontes de coleta indicadas, atribuiu-se o valor "1"; em caso contrário, atribuiu-se o valor "0". Foram somados os resultados dos itens, e o valor total foi equacionado pelo resultado máximo possível obtenível por cada empresa (15 pontos). Dessa razão, extraiu-se um índice de aderência às boas práticas de governança, que se encontra no intervalo fechado entre 0 e 1 . Destaca-se que esse instrumento foi replicado ainda por Lameira (2012), dessa vez examinando a relação entre o risco e a governança corporativa, nas empresas brasileiras de capital aberto.

\subsection{TRATAMENTO DOS DADOS}

Com o intuito de responder à questão suscitada nesta investigação, foram realizados o teste de Mann-Whitney e a regressão linear múltipla.

O teste de Mann-Whitney se faz necessário quando se deseja comparar a média de determinada variável (ordinal ou quantitativa) em amostras que tiveram a hipótese de normalidade violada (Fávero et al, 2009), como no presente estudo. Verificou-se a existência de diferença significativa do nível de governança entre as empresas internacionalizadas (Grupo 1) e as não internacionalizadas (Grupo 2), atribuindo-se 1 para as empresas internacionalizadas segundo as dimensões do Quadro 1, e 0 nos casos contrários.

Na sequência, aplicou-se a regressão linear múltipla. Segundo Hair et al (2009, p. 154), nessa técnica busca-se "usar as variáveis independentes cujos valores são conhecidos para prever os valores da variável dependente selecionada", como é a proposta desta pesquisa. Vale ressaltar, porém, que, antecedendo à regressão linear múltipla, foram verificados e validados os pressupostos tomados como condição para o seu desenvolvimento: normalidade dos resíduos, homocedasticidade, ausência de autocorrelação serial e multicolinearidade.

No modelo estatístico testado, foram ainda incrementadas algumas medidas de controle, para neutralizar efeitos que também podem impactar a governança corporativa das empresas. Essas variáveis são o tamanho (logaritmo do Ativo Total) e a idade (logaritmo da idade), disponível no Formulário Cadastral. O emprego de tais métricas respalda-se em pesquisas que trabalharam a governança corporativa e seus condicionantes (Silveira \& Barros, 2008; Procianoy \& Verdi, 2009; Mapurunga, Ponte \& Oliveira, 2013).

Dessa maneira, com base no modelo teórico de análise ilustrado na Figura 1 (referencial teórico), nas medidas de internacionalização (Quadro 1) e no nível de governança, segundo Lameira e Ness (2011) (Quadro 2), além das variáveis de controle, foi edificada a Equação 1, que compila as métricas do modelo quantitativo descrito, na forma a saber:

$$
\begin{gathered}
G O V_{i}=\beta O+\beta_{1} \text { Inter_CAP }+\beta_{2} \text { Inter_REC_EX }+\beta_{3} \text { Inter_MERC }+\beta_{4} \text { Inter_ } A D R_{i}+\beta_{5} T A M_{i}+\beta_{6} I D_{i}+\varepsilon_{i} \\
\text { Equação (1) }
\end{gathered}
$$


Em que:

GOV representa o nível de governança corporativa da empresa;

$\beta_{0} \quad$ é o intercepto;

$\beta_{1}$ Inter_CAP ${ }_{i}$ refere-se à internacionalização do capital social;

$\beta_{2}$ Inter_REC_EX compreende a internacionalização das receitas da empresas;

$\beta_{3}$ Inter_MERC , corresponde à internacionalização dos mercados de atuação (descentralização

dispersão geográfica da internacionalização);

$\beta_{4}$ Inter_ADR remete à internacionalização por meio da emissão de $A D R s ; \beta_{5}$

$\mathrm{TAM}_{i}$ mede o tamanho da empresa;

$\beta_{6} I D_{i}$ medida da idade da empresa; e

$\varepsilon_{i}$ é o termo de erro do modelo.

A partir da Equação 1, foram testados dois modelos: Modelo 1 - variáveis de internacionalização como dummies; e Modelo 2 - variáveis de internacionalização como contínuas). Assim, procura-se inferir se a presença da empresa no ambiente internacional (Modelo 1) e se, além disso, diferentes níveis de internacionalização (Modelo 2) têm impacto significativo na governança corporativa.

Utilizou-se o software Statistical Package for the Social Sciences 20.0 (SPSS), estabelecendo-se o nível crítico de significância ( $p$-value) 0,05 como aceitável.Cabe destacar ainda, a aplicação do software G*Power para verificar a adequabilidade da análise de influência ao grupo das 99 empresas. Destarte, considerando um tamanho de efeito moderado $(\mathfrak{f} 2=0,15)$, erro Tipo I a de 0,05 e erro Tipo II $\beta$ beta de 0,20, com número de seis preditores na regressão linear múltipla, chegou-se ao número de 98 para o tamanho da amostra e poder atual de 0,8035 , demonstrando, assim, a adequação do modelo estabelecido.

\section{RESULTADOS E DISCUSSÃO}

\subsection{AVALIAÇÃO DESCRITIVA DAS MEDIDAS DE INTERNACIONALIZAÇÃO E DA GOVER- NANÇA CORPORATIVA}

Na Tabela 1, encontra-se evidenciada a representatividade da internacionalização nas 99 empresas da amostra, bem como a estatística descritiva das variáveis de internacionalização.

Tabela 1: Estatística descritiva das variáveis de internacionalização

\begin{tabular}{|c|c|c|c|c|c|c|}
\hline Internacionalização & $\begin{array}{c}\text { Número de } \\
\text { Empresas }\end{array}$ & Média & Mediana & Desvio-padrão & Máximo & Mínimo \\
\hline Do Capital Social & 66 & $13,6 \%$ & $5,7 \%$ & $18,5 \%$ & $84,2 \%$ & $0,0 \%$ \\
\hline Das Receitas & 36 & $10,8 \%$ & $0,0 \%$ & $22,5 \%$ & $93,2 \%$ & $0,0 \%$ \\
\hline Dos Mercados & 30 & 2,4 & 0,0 & 5,9 & 33 & 0,0 \\
\hline Por meio de ADRs & 51 & 0,5 & 1,0 & 0,5 & 1,0 & 0,0 \\
\hline
\end{tabular}

Fonte: Dados da pesquisa.

Na Tabela 1, percebe-se que as maiores empresas de capital aberto do Brasil, em sua maioria, internacionalizaram-se através do capital social e da emissão de ADRs. Apenas um terço da amostra, aproximadamente, internacionalizou-se exportando ou se instalando em outros países. Isso corrobora a afirmação de Smaniotto, Paiva e Vieira $(2012$, p. 16) de que a internacionalização "é um tema recente no ambiente empresarial brasileiro", já que a internacionalização das empresas da amostra pode ser verificada pelos processos menos complexos representados pela participação dos investidores estrangeiros no capital social e pelas vendas ao mercado externo. 
A internacionalização do capital social, em geral, alcançou resultados inexpressivos, já que a média geral da participação estrangeira não passa de 13,6\% (20,4\% apenas em 66 empresas), sendo elevadas sua amplitude e a variabilidade. Mesmo com a maior quantidade de empresas, essa dimensão da internacionalização detém metade das empresas com participação igual ou inferior a 5,7\%. Os acionistas estrangeiros controlam 23 das 99 empresas da amostra, sendo os Estados Unidos o investidor de maior representatividade (44\% dos investidores).

No que tange à internacionalização das receitas, são 36 as empresas que exportam, com média de aproximadamente 30\%. Esse resultado diverge da afirmação de Floriani e Fleury (2012) segundo a qual a exportação é o meio mais frequente de internacionalização. Permanece a elevada dispersão dos dados, destacando-se uma das observações com valores superiores a 93\% (OGX) do volume total de suas receitas como estrangeiras.

Quanto à internacionalização dos mercados, apenas 30 empresas possuem instalações em outros países, com uma média de 8,1 países por empresa. O maior nível de dispersão geográfica pertence à empresa Vale, que possui instalações em 33 países, conforme identificado em seu Formulário de Referência.

A emissão de ADRs como meio de internacionalização é uma medida amplamente discutida na literatura (Procianoy \& Verdi, 2009; Souza, Murcia \& Marcon, 2011; Mapurunga, Ponte \& Oliveira, 2013; Santos, Almeida \& Bezerra, 2013), sendo também entendida como uma medida relacionada à adesão de padrões rígidos de governança corporativa. Na amostra analisada, mais de 50\% das empresas internacionalizou-se sob essa dimensão.

Adaptado para esta pesquisa, o índice de Lameira e Ness (2011) ajudou a descrever o nível de atendimento de boas práticas de governança corporativa pelas 99 empresas investigadas. Obtiveram-se uma média e uma mediana elevadas (62\% e $60 \%$, respectivamente). A empresa Mills atingiu o maior resultado (87\%, aproximadamente), enquanto o valor mínimo observado foi de $26,7 \%$. Ressalta-se que os resultados de Lameira e Ness (2011), nos anos 2003 a 2008, com uma amostra de 454 companhias, foram de 10,51\% e 9,11\% (médias máximas e mínimas, nessa ordem). Essas inferências revelam-se importantes na medida em que níveis mais altos de governança corporativa podem associar-se ao "desenvolvimento de melhores estruturas organizacionais e à busca de uma melhor dinâmica no seu funcionamento" (Lameira \& Ness, 2011, p. 34).

Já uma análise mais específica da governança corporativa das empresas do estudo é descrita na Tabela 2, em que o escopo de avaliação amplia-se ao nível das cinco dimensões e dos 15 itens (ver Quadro 2). Para Lameira e Ness (2011), esses aspectos passaram a ser bastante apreciados pelos investidores, em relação às empresas, quando da tomada de decisão.

Tabela 2: Percentuais de atendimento por dimensão e item de governança corporativa

\begin{tabular}{|c|c|c|c|}
\hline $\begin{array}{l}\text { Dimensão da governança } \\
\text { corporativa }\end{array}$ & $\begin{array}{l}\text { Atendimento por dimensão } \\
(\%)\end{array}$ & Item & Atendimento por item (\%) \\
\hline \multirow{3}{*}{$\begin{array}{l}\text { 1. Estrutura de propriedade e } \\
\text { controle }\end{array}$} & \multirow{3}{*}{50,5} & 1.1 & 27,3 \\
\hline & & 1.2 & 58,6 \\
\hline & & 1.3 & 65,7 \\
\hline \multirow{3}{*}{$\begin{array}{l}\text { 2. Adequação ao ambiente } \\
\text { institucional }\end{array}$} & \multirow{3}{*}{80,8} & 2.1 & 80,8 \\
\hline & & 3.1 & 93,9 \\
\hline & & 3.2 & 99,0 \\
\hline \multirow{3}{*}{ 3. Auditoria e conselho fiscal } & \multirow{3}{*}{77,8} & 3.3 & 40,4 \\
\hline & & 4.1 & 12,1 \\
\hline & & 4.2 & 6,1 \\
\hline
\end{tabular}




\begin{tabular}{|c|c|c|c|}
\hline \multirow{3}{*}{$\begin{array}{l}\text { 4. Conselho de administração } \\
\text { e outros }\end{array}$} & \multirow{3}{*}{49,9} & 4.3 & 71,7 \\
\hline & & 4.4 & 85,9 \\
\hline & & 4.5 & 73,7 \\
\hline \multirow{3}{*}{$\begin{array}{l}\text { 5. Relacionamento com } \\
\text { investidores }\end{array}$} & \multirow{3}{*}{71,7} & 5.1 & 47,5 \\
\hline & & 5.2 & 67,7 \\
\hline & & 5.3 & 100,0 \\
\hline
\end{tabular}

Fonte: dados da pesquisa.

Da Tabela 2, depreende-se que as dimensões $2(80,8 \%), 3(77,8 \%)$ e $5(71,5 \%)$ obtiveram os maiores níveis de atendimento. Ao que parece, no geral, as empresas se preocupam em repassar ao investidor confiabilidade e transparência, cumprir pressões institucionais e investir em fiscalização e no relacionamento com o stakeholder. Por sua vez, as dimensões 1 (50,5\%) e $4(49,9 \%)$, diretamente atreladas ao problema do risco da assimetria informacional, que podem elevar os custos de transação, ainda demandam mais atenção pelas empresas.

No tocante aos itens, observa-se que quatro deles não alcançaram sequer metade do nível de atendimento: item 3.3 - presença de conselho fiscal permanente $(40,4 \%)$; item 1.1 - controle das ações ordinárias (27,3\%); item 4.1 - participação dos administradores nos lucros (12,1\%) e item 4.2 - independência do conselho de administração $(6,1 \%)$.

Como órgão de governança, o conselho fiscal tem, entre outras atribuições, a de fiscalizar as ações do conselho de administração, evitando, assim, os desvios de conduta e oportunismo. Outra deficiência, segundo os resultados, é a falta de incentivos de alinhamento de interesses, representada pelo baixo nível do item 4.1. As características descritas no item 1.1 demonstram a ocorrência de problemas de concentração acionária, que podem estar refletindo no resultado do item 4.2, já que os controladores devem estar indicando os conselheiros das empresas, prejudicando a qualidade da governança corporativa.

\subsection{INFERÊNCIAS SOBRE O TESTE DE DIFERENÇAS ENTRE MÉDIAS}

Antes da adoção do teste de diferenças entre médias da governança corporativa nos grupos 1 (empresas internacionalizadas) e 2 (empresas não internacionalizadas), conforme mencionado na metodologia, verificou-se, por meio do teste de Kolmogorov-Smirnov, que os percentuais de atendimento não seguiam a curva normal (Sig. =0,000). Desse ponto, o teste de Mann-Whitney confirmou-se como técnica potente na comparação das médias da amostra. Assim, a Tabela 3evidencia os resultados dos testes entre médias nas empresas dos grupos destacados, sob cada variável da internacionalização.

Tabela 3 - Teste de Mann-Whitney: governança corporativa nas empresas internacionalizadas (Grupo 1) e não internacionalizadas (Grupo 2)

\begin{tabular}{|c|c|c|c|c|c|c|c|c|}
\hline \multicolumn{2}{|c|}{ Internacionalização } & \multirow{2}{*}{$\frac{\mathbf{N}}{66}$} & \multirow{2}{*}{$\begin{array}{c}\begin{array}{c}\text { Média do } \\
\text { Rank }\end{array} \\
52,37\end{array}$} & \multirow{2}{*}{$\begin{array}{c}\begin{array}{c}\text { Soma dos } \\
\text { Ranks }\end{array} \\
3456,50\end{array}$} & \multirow{3}{*}{$\begin{array}{c}\begin{array}{c}\text { Mann- } \\
\text { Whitney }\end{array} \\
932,50\end{array}$} & \multirow{3}{*}{$\begin{array}{c}\text { Wilcoxon W } \\
1493,50\end{array}$} & \multirow{3}{*}{$\begin{array}{c}\mathbf{Z} \\
-1,183\end{array}$} & \multirow{3}{*}{$\begin{array}{c}\begin{array}{c}\text { Asymp. } \\
\text { Sig. } \\
\text { (2-tailed) }\end{array} \\
0,237\end{array}$} \\
\hline \multirow{2}{*}{$\begin{array}{l}\text { Do capital } \\
\text { social }\end{array}$} & Grupo 1 & & & & & & & \\
\hline & Grupo 2 & 33 & 45,26 & 1493,50 & & & & \\
\hline \multirow{2}{*}{ Das receitas } & Grupo 1 & 36 & 60,00 & 2160,00 & \multirow{2}{*}{774,00} & \multirow{2}{*}{2790,00} & \multirow{2}{*}{$-2,667$} & \multirow{2}{*}{$0,008(*)$} \\
\hline & Grupo 2 & 63 & 44,29 & 2790,00 & & & & \\
\hline \multirow{2}{*}{ Dos mercados } & Grupo 1 & 30 & 58,32 & 1749,50 & \multirow{2}{*}{785,50} & \multirow{2}{*}{3200,50} & \multirow{2}{*}{$-1,935$} & \multirow{2}{*}{$0,053(* *)$} \\
\hline & Grupo 2 & 69 & 46,38 & 3200,50 & & & & \\
\hline \multirow{2}{*}{$\begin{array}{c}\text { Por meio de } \\
\text { ADRs }\end{array}$} & Grupo 1 & 51 & 50,72 & 2586,50 & \multirow{2}{*}{1187,50} & \multirow{2}{*}{2363,50} & \multirow{2}{*}{$-0,260$} & \multirow{2}{*}{0,795} \\
\hline & Grupo 2 & 48 & 49,24 & 2363,50 & & & & \\
\hline
\end{tabular}


Com base nos resultados dispostos na Tabela 3, pode-se verificar que, dentre as quatro dimensões de análise da internacionalização, duas apontaram uma significativa diferença na comparação entre as empresas internacionalizadas (Grupo 1) e as empresas não internacionalizadas (Grupo 2): internacionalização das receitas e dos mercados. Ou seja, é possível depreender que negociar e se instalar no ambiente internacional pressupõem a adesão de boas práticas de governança, provavelmente devido às pressões institucionais a que se submetem as empresas nos países estrangeiros.

De acordo com os pressupostos da ECT, a governança mitiga os riscos do oportunismo e aproxima o stakeholder estrangeiro, graças à percepção de redução dos custos de transação. A presença de investidor internacional e a negociação no mercado dos EUA, por outro lado, não se mostraram distintas significativamente, apesar de as médias do rank serem maiores no Grupo 1, levando a crer que sob esses aspectos de internacionalização, a governança nos grupos 1 e 2 guarda semelhança. Maia, Vasconcelos e De Luca (2013) encontraram resultado em que a governança corporativa era um sinalizador da presença de investidor internacional no capital social da empresa.

\subsection{ANÁLISE DE INFLUÊNCIA DA INTERNACIONALIZAÇÃO NA GOVERNANÇA CORPO- RATIVA}

Após as evidências encontradas na análise do teste de diferenças entre médias (tópico 4.2), em que as empresas internacionalizadas (Grupo 1) registram os maiores níveis médios de boas práticas de governança corporativa, resta verificar a influência da internacionalização no nível da governança corporativa das empresas, conforme proposto no modelo teórico de análise desenvolvido na pesquisa (Figura 1).

Desse modo, foi delineada a regressão linear múltipla, com o intuito de se comprovar o efeito da influência das quatro variáveis de internacionalização (Quadro 1) na variável governança (Quadro 2). Na Tabela 4, dispõem-se os resultados da regressão, sendo testados dois modelos distintos. No Modelo 1 , as variáveis de internacionalização são dummies, pois se avalia, a priori, se a participação da empresa no ambiente internacional, independentemente do grau, influencia a adoção de boas práticas de governança. Já no Modelo 2, as variáveis são contínuas, pois se procura inferir se os níveis de internacionalização têm influência no nível de governança corporativa das empresas.

Tabela 4: Resultados da regressão linear múltipla para os modelos 1 e 2

\begin{tabular}{|c|c|c|c|c|c|c|c|c|}
\hline \multirow{2}{*}{ Variável } & \multicolumn{4}{|c|}{ Modelo 1} & \multicolumn{4}{|c|}{ Modelo 2} \\
\hline & Beta & $\mathbf{T}$ & Sig. & VIF & Beta & $\mathbf{T}$ & Sig. & VIF \\
\hline Constante & - & 7,321 & $0,000\left(^{*}\right)$ & - & - & 6,419 & $0,000(*)$ & - \\
\hline Inter_CAP & 0,230 & 2,446 & $0,016\left(^{* *}\right)$ & 1,046 & $-0,021$ & $-0,207$ & 0,837 & 1,068 \\
\hline Inter_REC_EX & 0,293 & 2,764 & $0,007\left(^{*}\right)$ & 1,326 & 0,199 & 1,731 & $\left.0,087^{(* * *}\right)$ & 1,339 \\
\hline Inter_MERC & 0,169 & 1,588 & 0,116 & 1,340 & 0,060 & 0,480 & 0,632 & 1,593 \\
\hline Inter_ADR & 0,052 & 0,499 & 0,619 & 1,301 & 0,042 & 0,365 & 0,716 & 1,324 \\
\hline TAM & $-0,239$ & $-2,142$ & $0,035\left(^{* *}\right)$ & 1,465 & $-0,199$ & $-1,596$ & 0,114 & 1,571 \\
\hline ID & $-0,222$ & $-2,250$ & $0,027\left(^{* *}\right)$ & 1,146 & $-0,161$ & $-1,514$ & 0,133 & 1,145 \\
\hline $\mathbf{R}$ & 0,468 & Du & Natson & 1,840 & $\mathbf{R}$ & 0,307 & $\begin{array}{l}\text { Durbin- } \\
\text { Watson }\end{array}$ & 1,823 \\
\hline $\mathbf{R}^{2}$ & 0,219 & & & 4,297 & $\mathbf{R}^{2}$ & 0,094 & $\mathbf{F}$ & 1,596 \\
\hline$R^{2}$ ajustado & 0,168 & & & $0,001\left(^{*}\right)$ & $R^{2}$ ajustado & 0,035 & Sig. & 0,157 \\
\hline
\end{tabular}


Na Tabela 4, apenas o Modelo 1 se mostrou significativo, com poder explicativo de $16,8 \%$. Sobre esse modelo, foram descartados os problemas de autocorrelação dos resíduos (Durbin-Watson de 1,840). Pelo teste de Pesarán-Pesarán, o modelo se mostrou homocedástico (Sig. $=0,293$ ) e seus resíduos se revelaram normais pelo teste de Kolmogorov-Smirnov (Sig. $=0,835$ ). As estatísticas de VIF (Variance Inflation Factor) demonstram não haver problemas significativos de multicolinearidade. Dito isso, de acordo com o Modelo 1, a internacionalização do capital social e das receitas da empresa influencia positivamente a estrutura de governança corporativa nas empresas da amostra.

Não se pode fazer qualquer inferência estatística sobre o Modelo 2,já que este não se mostrou significativo (Sig. = 0,157).

Assim, das conclusões que podem ser obtidas, observa-se que a internacionalização em si demonstrou ser um imperativo da governança corporativa, não importando o grau de internacionalização em cada uma das dimensões analisadas, ou seja, a intensidade das estratégias de internacionalização das empresas. Stal (2010), Arantes, Mottin e Gomes (2010) e Duarte, Cardozo e Vicente (2012) argumentam sobre os padrões de comportamento, em se tratando da internacionalização e da adoção de práticas de governança, reforçando-se a institucionalização das empresas ao ingressarem no mercado internacional. Assim, não é relevante, por exemplo, se a empresa exporta mais ou menos, pois ela terá que atender aos mesmos requisitos impostos a todas as empresas internacionalizadas, de maneira uniforme, para se tornar competitiva e atrair cada dia mais o stakeholder estrangeiro. Isso é o que afirmam Heijltjes, Olie e Glunk (2003) e Faro e Faro (2010), ao definir a internacionalização como conduta das empresas e investidores internacionais direcionadas para a integração econômica dos estados.

Os resultados em relação ao constructo internacionalização são reforçados pelos estudos de Silveira (2008), Silveira e Barros (2008), Souza, Murcia e Marcon (2011), e contrários às evidências de Mapurunga, Ponte e Oliveira (2013) e Santos, Almeida e Bezerra (2013), que utilizam apenas a emissão de ADRs como proxy. Outros estudos, como os de Maia, Vasconcelos e De Luca (2013) e Santos, Vasconcelos e De Luca (2013), examinaram a internacionalização do capital social, mas não investigaram qualquer relação de influência.

Em geral, pode-se concluir que a internacionalização tem impacto positivo significativo na adoção de práticas de governança corporativa, considerando as dimensões internacionalização do capital social e internacionalização das receitas. Entretanto, não se verificou relação de influência quanto às dimensões internacionalização dos mercados e internacionalização por meio de emissão de ADRs. A partir desse resultado, pode-se entender que a adoção de boas práticas de governança corporativa sugere a redução dos custos de transação inerentes ao processo de internacionalização, contribuindo para a aproximação da empresa com o ambiente internacional.

Dessa forma, pode-se apontar que a governança corporativa se torna requisito para o processo de internacionalização, na medida em que promove o ajuste ou o alinhamento entre as transações da empresa e os interesses junto ao mercado internacional. De acordo com Williamson (2005), se a transação é a unidade mínima de análise das firmas contemporâneas, considerando como atributos das transações a especificidade dos ativos nelas envolvidos, a incerteza e a frequência a elas inerente, então, as estruturas de governança devem se alinhar às transações (e o contrário também). Destaca-se que, à luz da Economia dos Custos de Transação, este estudo leva em conta que a governança corporativa, com status de recurso específico da empresa requerido pelo mercado internacional, pode favorecer a atuação empresarial no ambiente externo. 


\section{CONSIDERAÇÕES FINAIS}

No contexto das maiores empresas brasileiras de capital aberto, esta pesquisa analisou a influência da internacionalização na governança corporativa à luz da ECT. Tratando-se a internacionalização sob múltiplas dimensões, procurou-se suprir lacuna existente nas pesquisas acerca das duas temáticas, conjuntamente, em que prevalece a abordagem unidimensional. Contribuiu-se, ainda, para a construção de um modelo teórico de avaliação, que foi confirmado mediante aplicações empíricas desenvolvidas neste estudo.

Com a análise descritiva, verificou-se que a internacionalização atinge diferentemente as empresas, em proporção e intensidade. Os aspectos mais considerados pelas empresas ao se internacionalizarem são o capital social, a emissão de ADRs, as exportações e a presença física (instalação) da empresa em outros países, nessa ordem de importância. Segundo a literatura, este último é aquele que demanda mais risco e comprometimento da empresa, o que pode justificar o resultado encontrado. Todavia, a exportação, apontada como meio mais frequente de internacionalização, não apresentou resultados convergentes com os de outros estudos.

Na governança corporativa, foram observados níveis médios de comprometimento com esse instrumento de mitigação de riscos relacionados ao conflito de interesses e à assimetria informacional, fatores que tendem a elevar os custos de transação. Das cinco dimensões da governança, consideradas no estudo, obtiveram destaque adequação ao ambiente institucional, auditoria e conselho fiscal e relacionamento com investidores, o que demonstrou que as empresas estudadas se preocupam com a legitimação e aceitação de suas práticas no mercado, ou seja, com a percepção do stakeholder sobre suas ações. No ambiente internacional, esses pontos ganham relevância, porque a existência de uma forte estrutura de governança pode facilitar o ingresso da empresa no mercado externo e na captação de recursos.

Com o teste de diferenças entre médias, observou-se que as empresas que vendem para o exterior e se instalam em outros países registram média de atendimento das práticas de governança corporativa significativamente superior àquela apresentada pelas empresas que não adotam tais estratégias. Com a regressão linear múltipla, as conclusões foram ainda mais pertinentes, pois se constatou que investidores estrangeiros (internacionalização do capital social) e a exportação (internacionalização das receitas) influenciam positivamente a adoção de práticas de governança corporativa. Todavia, apenas a inserção da empresa no mercado internacional, segundo o modelo testado, não implica melhor nível de governança.

Esse resultado é coerente, na medida em que não deveria haver distinção de estruturas de governança nas empresas que integram o mercado internacional, já que a tendência é o comportamento uniforme dos agentes econômicos nesse macroambiente. Sob essa perspectiva, dois pontos merecem destaque: primeiro, haveria uma tendência à institucionalização das práticas de governança, pois o mercado (incluindo o internacional) escolhe as empresas "mais seguras" para investir; e segundo, essa "segurança" pode ser atribuída à governança corporativa, pois, ao mitigar problemas de conflitos de interesse e assimetria informacional, a empresa reduz, indiscutivelmente, os custos de transação.

Cabe mencionar que a relação entre os dois constructos do estudo - governança corporativa e internacionalização - foi verificada tanto sob o enfoque teórico quanto sob o estatístico, na medida em que se confirmou o impacto da inserção internacional das empresas na demanda à adoção de 
mecanismos de governança, considerando duas das dimensões pesquisadas - internacionalização do capital social e internacionalização das receitas.

Como já destacado, a pesquisa considera a estrutura de governança corporativa como ativo específico da empresa que pode, dentre outros, favorecer a liquidez das transações e a inserção no mercado externo, à luz da Economia dos Custos de Transação. Ressalta-se que alguns atributos das transações como a incerteza e a frequência não foram abordados no estudo, sendo essa uma das suas limitações.

A pesquisa avança nos campos teórico e prático, porém com limitações inerentes ao método de desenvolvimento da investigação. Assim, sugere-se que, tanto no constructo internacionalização, como na governança corporativa, há que se ponderar sobre a ampliação das variáveis. A análise em questão cobre apenas um período, e o estudo pode ser replicado em um contexto longitudinal, suscitando inferência acerca do efeito temporal dos dados. Para além, sugere-se uma amostra que contemple todas as empresas brasileiras listadas na BM\&F Bovespa. Destaca-se, ainda, a possibilidade de análise comparativa entre empresas de países em desenvolvimento e empresas de países desenvolvidos, já que estes possuem mercados de capitais dotados de estrutura de proteção e monitoramento superior. Dessa forma, ressalta-se que as inferências aqui apontadas só podem ser generalizadas se, e somente se, resguardadas as devidas limitações decorrentes do método adotado. 


\section{REFERÊNCIAS}

Andrade, G. A. R. (2008). Estudo econométrico dos efeitos da migração para OIGC: índice de ações com governança corporativa diferenciada da Bovespa. Revista Eletrônica de Negócios Internacionais, 3(1), pp. 39-53.

Arantes, B. R., Mottin, A. \& Gomes, J. S. (2010). O impacto da internacionalização sobre sistemas de controle gerencial de empresas brasileiras: o caso da Método Engenharia e da Totvs S/A. Revista Contabilidade Vista \& Revista, 21(4), pp. 63-87.

Bardin, L. (1977). Análise de conteúdo. Lisboa: Edições 70.

Burgman, T. A. (1996). An empirical examination of multinational corporate capital structure. Journal of International Business Studies, 27(3), pp. 553-570.

Carneiro, J. \& Dib, L. A. (2007). Avaliação comparativa do escopo descritivo e explanatório dos principais modelos de internacionalização de empresas. Revista Eletrônica de Negócios Internacionais, 2(1), pp. $1-25$.

Coase, R. H. (1937). The nature of the firm. Economica, New Series, 4(16), pp. 386-405.

Cunha, T. S. (2012). Governança corporativa e a participação dos investidores estrangeiros nas companhias abertas latino americanas. 36 f. Dissertação de Mestrado em Economia e Finanças - Escola de Economia de São Paulo, Fundação Getúlio Vargas, São Paulo.

Domeneghetti, D. \& Meir, R. (2009). Ativos intangíveis: como sair do deserto competitivo dos mercados e encontrar um oásis de valor e resultados para a sua empresa. 3. ed. Rio de Janeiro: Elsevier.

Duarte, E., Cardozo, M. A. \& Vicente, E. F. R. (2012). Governança: uma investigação da produção científica brasileira no período de 2000 a 2009. Contabilidade, Gestão e Governança, 15(1), pp. 115-127.

Export Manager. (2008). Estratégias de internacionalização. São Paulo: Export Manager Business School. Disponível em:

<http://www.exportmanager.com.br/pages/titulos/pdf/estrategias_de_internacionalizacao.pdf >. Acesso em: 29 out. 2013.

Faro, R. \& Faro, F. (2010). Competitividade no comércio internacional: acesso das empresas brasileiras aos mercados globais. São Paulo: Atlas.

Fávero, L. P., Belfiore, P., Silva, F. L. \& Chan, B. L. (2009). Análise de dados: modelagem multivariada para tomada de decisões. 4. ed. Rio de Janeiro: Elsevier. 
Floriani, D. E. \& Fleury, M. T. (2012). O efeito do grau de internacionalização nas competências internacionais e no desempenho financeiro da PME brasileira. Revista de Administração Contemporânea - RAC, 16(3), pp. 438-458.

Gomes, J. S. \& Martinewski, A. L. (2001). Contabilidade de gestão em empresas internacionalizadas: algumas evidências de empresas brasileiras. Revista Contabilidade Vista \& Revista, 12(1), pp. 9-30.

Hair Jr., J. F., Black, W. C., Babin, B. J., Anderson, R. E. \& Tathan, R. L. (2009). Análise multivariada de dados. 6. ed. Porto Alegre: Bookman.

Hassel, A., Höpner, M., Kurdelbusch, A., Rehder, B. \& Zugehör, R. (2003). Two dimensions of the internationalization of firms. Journal of Management Studies, 40(3), pp. 701-720.

Heijltjes, M., Olie, R. \& Glunk, U. (2003). Internationalization of top management teams in Europe. European Management Journal, 21(1), pp. 89-97.

Hoque, Z. (2010). Methodological issues in accounting research: theories and methods. London: Spiramus.

Kontinen, T. \& Ojala, A. (2010). The internationalization of family business: a review of extant research. Jornal of Family Business Strategy, 1, pp. 97-107.

Lameira, V. J. (2012). As relações entre governança e risco nas companhias abertas brasileiras. Revista Brasileira de Gestão de Negócios - RBGN, 14(42), pp. 7-25.

Lameira, V. J. \& Ness Jr., W. L. (2011). Os determinantes da qualidade da governança praticada pelas companhias abertas brasileiras. Revista de Negócios, 16(3), pp. 33-52.

Lin, W. (2012). Family ownership and internationalization processes: internationalization pace, internationalization scope, and internationalization rhythm. European Management Journal, 30, pp. 47-56.

Lopes, R. S. S. \& Gomes, J. S. (2013). O impacto da internacionalização sobre os sistemas de controle gerencial de empresas do setor de indústrias têxtil brasileiro: estudos de casos no segmento de moda feminina. Revista Universo Contábil, 9(2), pp. 6-26.

Machado-da-Silva, C. L. \& Fernandes, B. H. R. (1999). O impacto da internacionalização nos esquemas interpretativos dos dirigentes dos dirigentes do Banco Bamerindus. Revista de Administração de Empresas, 39(1), pp. 14-24.

Maia, A. B. G. R., Vasconcelos, A. C. \& De Luca, M. M. M. (2013). Governança corporativa e internacionalização do capital social das companhias brasileiras do setor de construção e transportes. Revista Eletrônica de Negócios Internacionais, 8(2), pp. 40-60. 
Mapurunga, P. V. R., Ponte, V. M. R. \& Oliveira, M. C. (2013). Determinantes das práticas de governança corporativa: um estudo nas empresas registradas na CVM. In: Encontro Nacional da Associação Nacional de Pós-Graduação e Pesquisa em Administração - EnANPAD, 37., Rio de Janeiro, Anais ... Rio de Janeiro: EnANPAD.

Masullo, D. G. \& Lemme, C. F. (2009). Um exame da relação entre o nível de internacionalização e a comunicação ambiental nas grandes empresas brasileiras de capital aberto. Revista Eletrônica de Administração, 15(3), pp. 557-580.

Milan, G. S., Eckert, A., Mello, C. B. C. \& Giovanella, R. (2013). A aquisição de uma empresa brasileira como estratégia de internacionalização de uma multinacional fabricante de material elétrico: o processo e principais resultados. REBRAE - Revista Brasileira de Estratégia, 6(2), pp. 121-136.

Mitter, C., Duller, C., Feldbauer-Durstmüller, B. \& Kraus, S. (2012). Internationalization of family firms: the effect of ownership and governance. Review of Managerial Science, 6(4), pp. 1-28.

Muller, W. R. I. (2008). A internacionalização de empresas brasileiras e a criação de valor para o acionista. 125 f. Dissertação de Mestrado em Administração de Empresas - Pontifícia Universidade Católica de São Paulo, São Paulo.

Nickels, W. G. \& Wood, M. B. (1999). Marketing: relacionamentos, qualidade, valor. Rio de Janeiro: LTC.

Oesterle, M., Richta, H. N. \& Fish, J.H. (2013). The influence of ownership structure on internationalization. International Business Review, 22, pp. 187-201.

Ojah, K. \& Mokoaleli-Mokoteli, T. (2012). Internet financial reporting, infrastructures and corporate governance: an international analysis. Review of Development Finance, 2, pp. 69-83.

Okimura, R. T. (2003). Estrutura de propriedade, governança corporativa, valor e desempenho das empresas no Brasil. 120 f. Dissertação de Mestrado em Administração - Faculdade de Economia, Administração e Contabilidade, Universidade de São Paulo, São Paulo.

Platchek, R. B., Floriani, D. E. \& Borini, F. M. (2012). A influência do grau de internacionalização no desempenho das empresas têxteis. Revista Gestão Organizacional, 5(1), pp. 70-81.

Procianoy, J. L. \& Verdi, R. S. (2009). Adesão aos novos mercados da Bovespa: Novo Mercado, Nível 1 e Nível 2 - Determinantes e consequências. Revista Brasileira de Finanças, 7(1), pp. 107-136.

Reeb, D. M., Kwok, C. C. Y. \& Baek, H. Y. (1998). Systematic risk of the multinational corporation. Journal of International Business Studies, 29(2), pp. 263-279.

Ruigrok, W. \& Wagner, H. (2003). Internationalization and performance: an organizational learning perspective. Management International Review, 43, pp. 63-83. 
Santos, J. G. C., Vasconcelos, A. C. \& De Luca, M. M. M. (2013). Perfil da inovação e da internacionalização de empresas transnacionais. Revista de Administração e Inovação - RAl, 10(1), pp. 198-211.

Santos, J. R. (2009). Teorias da internacionalização: aplicação a um estudo de caso. 122 f. Dissertação de Mestrado em Gestão - Departamento de Economia, Gestão e Engenharia Industrial, Universidade de Aveiro, Aveiro.

Santos, P. S. A., Almeida, D. M. \& Bezerra, F. A. (2013). Grau de disclosure voluntário e nível de governança corporativa no caso das companhias brasileiras de capital aberto: um estudo de relação. Revista de Administração e Contabilidade - ReAC, 5(1), pp. 4-21.

Sherman, H. D., Kashlak, R. J. \& Joshi, M. P. (1998). The effect of the board and executive committee characteristics on the degree of internationalization. Journal of International Management, 4, pp. 311-335.

Silveira, H. P. (2008). Dupla listagem e estrutura de capital - uma análise das empresas brasileiras emissoras de ADRs. 141 f. Tese de Doutorado em Administração - Faculdade de Economia, Administração e Contabilidade, Universidade de São Paulo, São Paulo.

Silveira, A. D. M. \& Barros, L. A. B. C. (2008). Determinantes da qualidade da governança corporativa das companhias abertas brasileiras. Revista Eletrônica de Administração - REAd, Edição 61, 14(3), pp. 1-29.

Singh, D. A. \& Gaur, A. S. (2013). Governance structure, innovation and internationalization: evidence from India. Journal of International Management, 19, pp. 300-309.

Smaniotto, E., Paiva, E. L. \& Vieira, L. M. (2012). Estratégia de internacionalização através de upgrading funcional. Revista Contemporânea de Economia e Gestão, 10(1), pp. 15-29.

Souza, F. C., Murcia, F. D. \& Marcon, R. (2011). Bonding Hypothesis: análise da relação entre disclosure, governança corporativa e internacionalização de companhias abertas no Brasil. Contabilidade, Gestão e governança, 14(2), pp. 62-81.

Stal, E. (2010). Internacionalização de empresas brasileiras e o papel da inovação na construção de vantagens competitivas. Revista de Administração e Inovação, 7(3), pp. 120-149.

Sullivan, D. (1994). Measuring the degree of internationalization of a firm. Journal of International Business Studies, 34(2), pp. 165-186.

Wang, C-H., Hsu, L-C. \& Fang, S-R. (2008). The determinants of internationalization: evidence from the Taiwan high technology industry. Technological Forecasting \& Social Change, 75, pp. 1388-1395.

Williamson, O. E. (1996). The mechanisms of governance. New York: Oxford.

Xiao, S. S., Jeong, I., Moon, J. J., Chung, C. C. \& Chung, J. (2013). Internationalization and performance of firms in china: moderating effects of governance structure and the degree of centralized control. Journal of International Management, 19, pp.118-137. 